\title{
Where There Is (No) Smoke, There Is Still Fire: a Review of Trends, Reasons for Use, Preferences and Harm Perceptions of Adolescent and Young Adult Electronic Cigarette Use
}

\author{
Priya Sarin Gupta ${ }^{1,2}$ (D) Kelly M. Kalagher ${ }^{1}$ \\ Accepted: 12 April 2021 / Published online: 10 May 2021 \\ (C) The Author(s), under exclusive licence to Springer Science+Business Media, LLC, part of Springer Nature 2021
}

\begin{abstract}
Purpose of the review To review the current prevalence, trends, perceptions, and effects of e-cigarette or vaping product use associated lung injury (EVALI) on e-cigarette use among US adolescents and young adults.

Recent findings COVID-19 diagnosis was more likely among the current/ever dual cigarette and e-cigarettes users, as well as ever e-cigarette only users. Additionally, the EVALI outbreak may have influenced harm perceptions, as daily nicotine vaping declined significantly from 2019 to 2020, and more youth and young adults perceived vaping as harmful.

Summary The prevalence of e-cigarette use, specifically flavored use, remains high among adolescents and young adults, which is concerning due to the short-term and unknown long-term effects of e-cigarettes and their association with future cigarette and other substance use.
\end{abstract}

Keywords Adolescent vaping · Youth and young adult e-cigarette use $\cdot$ Youth flavored e-cigarette use $\cdot$ Vaping and COVID-19 . EVALI

\section{Introduction}

Electronic cigarettes, also known as e-cigarettes, Electronic Nicotine Delivery Systems (ENDS), or e-hookah, are devices that deliver nicotine without the combustion of tobacco [1-3]. Invented by Chinese pharmacist Hon Lik in 2003, e-cigarettes have gained widespread popularity throughout the USA over the past decade after emerging into the US market in 2007 [3, 4]. These devices heat an e-liquid, commonly containing propylene glycol, nicotine, flavoring agents, and other additives into an inhaled aerosol [1, 3]. E-cigarette aerosols have been shown to contain heavy metals and other carcinogenic substances, although these levels are generally lower than what is

This article is part of the Topical Collection on Adolescent Medicine

Priya Sarin Gupta

psgupta@mgh.harvard.edu

1 Division of General Internal Medicine, Department of Medicine, Massachusetts General Hospital, 100 Cambridge Street, Suite 1600, Boston, MA 02114, USA

2 Harvard Medical School, Boston, MA, USA in combustible cigarettes $[5,6]$. These devices are highly variable in design, shape, and size and can deliver varying levels of nicotine $[2,5,7]$ While these products have been marketed as a healthier alternative to smoking combustible tobacco, more is to be learned about their long-term safety and efficacy as a smoking cessation aide $[1,3,7]$ in adolescents. Ecigarettes may benefit long-term tobacco users through harm reduction.

\section{Prevalence of e-cigarette use}

E-cigarettes are currently the most commonly used tobacco product among youth [8]. In the 2019 National Youth Tobacco Survey (NYTS), a nationally representative sample of 19,018 middle and high school students, the prevalence of current ecigarette among US high school and middle school students was about 27.5 and $10.5 \%$, respectively [9॰]. The 2020 NYTS data show a decline back to 2018 levels. Of the current ecigarette users, over half of high schoolers and middle schoolers reported JUUL as their usual e-cigarette brand [9॰]. Among the exclusive e-cigarette users (no dual use of tobacco cigarettes) about $72 \%$ of high schoolers and $60 \%$ of middle schoolers used 
flavored e-cigarettes, with fruit, menthol or mint, and candy, desserts, or other sweets reported as the most common flavors [9•]. Data from the 2019 Monitoring the Future study, another nationally representative survey demonstrate a high prevalence of nicotine and cannabis vaping $\left[10^{\bullet}, 11^{\bullet}\right]$. Current nicotine vaping reported among the US $8^{\text {th }}, 10^{\text {th }}$, and $12^{\text {th }}$ graders were $9.0,20.2$, and $25.4 \%$, respectively [11•]. Current cannabis vaping among the US $8^{\text {th }}, 10^{\text {th }}$, and $12^{\text {th }}$ graders were $3.9,12.6$, and $14 \%$, respectively [10 $[$.

\section{Rise of e-cigarette use}

Studies show both nicotine and cannabis use among adolescents and young adults have increased significantly over the years $[10 \bullet, 11 \cdot 12-15]$. Cullen and colleagues analyzed data from the 2011-2018 National Youth Tobacco Survey (NYTS), a cross-sectional, voluntary, school-based, self-administered, pencil-and-paper survey of US middle and high school students [12]. They found that current e-cigarette use among high school students, defined as having used an ecigarette in the past 30 days, increased significantly from 1.5 to $20.8 \%$ between 2011 and 2018 [12]. A significant increase was also seen among middle school students, rising from 0.6 to $4.9 \%$ between 2011 and 2018 [12]. Current e-cigarette use among high school students increased $78 \%$ from 2017 to 2018 , a rise that could be attributed to the recent popularity of discrete USB shaped devices, such as the JUUL $[12,16]$. As of 2019, JUUL was the most popular brand of e-cigarettes [17]. The Truth Longitudinal Cohort, a nationally representative sample of adolescents and young adults, showed a significant increase in ever and current e-cigarette use and JUUL use from 2018 to 2019 [13]. Vallone and colleagues also saw an increase in the frequency of past 30-day JUUL use from 2018 to 2019, with more participants reporting using JUUL 10-30 days [13]. Increasing JUUL prevalence and frequency of use among youth and young adults is particularly concerning given JUUL's nicotine salt-based 'pods' (e-cigarette cartridges), which provide exposure to high amounts of nicotine $[9 \bullet, 18]$. Disposable e-cigs are now on the rise in youth after the national ban on most other pod based systems in 2020 .

\section{E-cigarette use and subsequent tobacco and other substance use}

While this view is controversial, adolescent and young adult (AYA) e-cigarette use is associated with future cigarette use in some studies [19-21]. The 2013-2015 Population Assessment of Tobacco and Health Study (PATH), a nationally representative longitudinal cohort study of US youth, showed that participants who had never smoked a cigarette (cigarette naïve) but were ever electronic cigarette users at Wave 1 (2013-2014) were more than four times more likely to engage in ever cigarette smoking at Wave 2 (2014-2015) [19]. Miech and colleagues also demonstrated an increased likelihood of cigarette smoking behaviors among recent vapers [20]. Using the data from the 2014-2015 Monitoring the Future Study, they showed that the youth who had never smoked a cigarette by 12th grade and were recent vapers at baseline were more than four times $[R R=4.78]$ more likely to report past-year cigarette smoking at follow-up [20]. The age of onset e-cigarette use has also been shown to be an important factor in predicting future tobacco use [21]. Youth who began using e-cigarettes in the $9^{\text {th }}$ grade or earlier were found to report more ever or lifetime cigarette smoking compared to individuals who never used e-cigarettes or those who began using e-cigarettes later in the 12th grade [21]. AYA ever ecigarette use is also associated with an increased likelihood of future marijuana and other illicit substance use [21-26].

However, it is important to emphasize that this view is controversial. The question is how many youth who never have experimented with tobacco products and start with ecigarettes become smokers. Most who try e-cigarettes have already tried other tobacco products. So, there is another side to the debate that argues that maybe e-cigarette use discourages some youth who are risk takers and trying tobacco products from becoming smokers. Clearly, more research is needed to fully understand the impact of e-cigarettes and future smokers before causality can be determined.

\section{Reasons for vaping}

Unlike adults, who often report quitting cigarettes as their primary reasons for e-cigarette use, adolescent and young adults are less likely to use for this reason [27]. In the Monitoring the Future 2015-2016 survey, only 7.3\% of youth reported vaping to replace cigarettes, while $29.4 \%$ endorsed 'Vaping for Experiment' and $63.4 \%$ endorsed 'Vaping for taste and entertainment' [28]. The top reasons for use consistently reported within the literature include experimentation/ curiosity, taste/flavors available, entertainment/enjoyment, or because someone they knew (i.e., friends or family) used ecigarettes [28-35].

\section{Flavor preferences and use}

Nontraditional flavors of e-cigarettes may be appealing due to their ability to mask the aversive taste of nicotine with sweet or cool sensory experiences [36•]. In a 2019 national sample of US middle and high schoolers, most current e-cigarette users reported use of flavored e-cigarettes, with fruit, menthol or mint, and candy, desserts, or other sweets being the most 
commonly reported flavors [9•]. The youth are more likely to initiate e-cigarette use with a non-traditional flavor compared to adults and are more likely to be interested in trying an ecigarette from a friend if it is flavored like candy, menthol, or fruit [36•, 37-39]. The 2013-2014 PATH study showed 81\% of youth reported that the first e-cigarette they used was flavored [38]. Additionally, adolescents and young adults are also more likely to prefer flavor fruit, alcohol, and other flavors, compared to adults who disproportionally favor tobacco, menthol/mint, spice, and coffee e-liquids [40]. Given the widespread use of flavored e-cigarettes by adolescents and young adults, a federal policy banning all cartridge-based ecigarette products (excluding menthol and tobacco flavors) was put into effect on February $6^{\text {th }}, 2020$ [41]. While a step in the right direction, this policy does little to hinder youth use [42]. Kid-friendly flavors in disposable and refillable cartridge devices not covered under this policy are still available in many states. Some states such as Massachusetts have taken more stringent action, banning all flavored e-cigarettes regardless of the type of device [43]. Continued efforts should be made to reduce the use of and access to flavored tobacco/ nicotine products [42].

\section{Harm perceptions}

Many youth and young adults harbor misconceptions about the harm and addictiveness associated with ecigarette use [44]. A 2014-2015 survey of $9^{\text {th }}$ and $12^{\text {th }}$ graders showed $19.05 \%$ of participants believed that smoke from e-cigarettes was water [44]. Studies show AYA also believes that e-cigarettes are less harmful and less addictive than regular cigarettes [44-48]. For example, the PATH 2012 and 2014 survey of students 6 to $12^{\text {th }}$ graders showed almost $75 \%$ believed that e-cigarettes were less harmful than cigarettes and $47 \%$ believed ecigarettes were less addictive than cigarettes [48]. While it may be beneficial for tobacco smokers to substitute with e-cigarettes, any form of tobacco use by the youth is unsafe [49]. Ever and current e-cigarette users have significantly lower harm and addiction perceptions compared to never users [46]. Studies also demonstrate that harm and addictiveness perceptions differ by flavor. Pepper and colleagues found that adolescents viewed flavored ecigarettes as less harmful to health than tobacco flavors [39]. In a 2018 survey of high school students, participants perceived fruit flavors as less likely to cause lung cancer, contain less harmful secondhand smoke and be more addictive compared to tobacco flavors [50]. These findings show that increased efforts should be made to educate the youth and young adults about the potential harm, addictiveness, and additives in e-cigarettes.

\section{Effects of e-cigarette or vaping product use associated lung injury}

In the summer of 2019, a nationwide outbreak of e-cigarette or vaping product use associated lung injuries (EVALI) increased safety concerns about the use of e-cigarettes [51, 52]. Fifty-two percent of the 2668 hospitalizations and deaths from EVALI were under 25 years old [53]. These highly publicized cases may have influenced perceptions about ecigarettes and their safety. The Monitoring the Future survey of $10^{\text {th }}$ and $12^{\text {th }}$ graders from 2017 to 2020 showed that students who perceived great harm from occasional nicotine vaping increased significantly from $21 \%$ in 2019 to $27 \%$ in 2020 [54*0]. Perceptions of the harm of regular vaping also increased significantly [54०•]. Daily vaping significantly declined from 2019 to 2020 [54••*. Even with this decline and increased awareness of the potential harms of vaping, youth use still remains high. It is important to note that the cause of EVALI was determined to be contaminants used in THC vaping products and not commercial e-cigarette use. So while EVALI discouraged e-cig use among the youth, a good thing, use of commercial e-cigarette containing nicotine only was not the cause.

\section{Vaping and COVID-19}

The effects of smoking and vaping on COVID-19 susceptibility are unknown [55]. A recent study showed a strong association between COVID-19 diagnosis and e-cigarette use in a survey of adolescents and young adults [56••]. Among the survey participants, COVID-19 diagnosis was 5 times more likely among ever only e-cigarette users, 7 times more likely among ever dual-users, and 6.8 times more likely among past 30 -day dual users [56••]. Additionally, COVID testing was 9 times more likely among past 30-day dual users, and 2.6 times more likely among past 30 -day e-cigarette only users [56••]. Future studies should explore these associations further, as they have a direct impact on health care providers in screening for e-cigarette use in COVID-19-affected youth.

\section{Conclusions}

E-cigarettes remain the most used tobacco product among youth and young adults. This is problematic not only because of the harms from nicotine exposure and other health risks associated with e-cigarette use, but e-cigarette use may be associated with future cigarette and other substance use. The main reasons for user use reported are attraction to flavors, entertainment/curiosity, and because someone they knew used e-cigarettes. Efforts should be made to educate the youth about the negative effects of e-cigarette use on their health 
and increase their awareness of potential harm. Health care providers and policymakers should continue to work to prevent access to and use of e-cigarettes.

\section{References}

Papers of particular interest, published recently, have been highlighted as:

- Of importance

•- Of major importance

1. Grana R, Benowitz N, Glantz S. (2013). Background paper on Ecigarettes (electronic nicotine delivery systems). Retrieved from https://escholarship.org/content/qt13p2b72n/qt13p2b72n.pdf. Accessed 12 Dec 2020.

2. Chaffee B. Electronic cigarettes: trends, health effects and advising patients amid uncertainty. Journal of the California Dental Association. 2019;42:85-92.

3. Grana R, Benowitz N, Glantz S. E-cigarettes: a scientific review. Circulation. 2014;129:1972-86. https://doi.org/10.1161/ CIRCULATIONAHA.114.007667.

4. Jessen B, Boykan R. Electronic cigarettes and youth in the United States: a call to action (at the local, national and global levels). Children. 2019;6:30. https://doi.org/10.3390/children6020030.

5. Prochaska J. The public health consequences of e-cigarettes: a review by the national academies of sciences. A call for more research, a need for regulatory action. Addiction. 2019;114:587-9. https://doi.org/10.1111/add.14478.

6. US Department of Health and Human Services. E-cigarette use among youth and young adults: a report of the Surgeon General. Atlanta, GA: US Department of Health and Human Services, CDC, National Center for Chronic Disease Prevention and Health Promotion, Office on Smoking and Health; 2016. https://e cigarettes.surgeongeneral.gov/documents/2016_SGR_Full Report_non-508.pdf. Accessed 12 Dec 2020.

7. Civiletto CW. Hutchison J. StatPearls: Electronic vaping delivery of cannabis and nicotine; 2020.

8. Chadi N, Hadland S, Harris S. Understanding the implications of the "vaping epidemic" among adolescents and young adults: a call for action. Subst Abus. 2019;40:7-10. https://doi.org/10.1080/ 08897077.2019.1580241.

9. Cullen K, Gentzke A, Sawdey M. e-cigarette use among youth in the United States, 2019. JAMA. 2019;322:2095-103. https://doi. org/10.1001/jama.2019.18387 A paper estimating the national prevalence of youth e-cigarette use in 2019.

10. Miech R, Patrick M, O'Malley P, Johnston L, Bachman J. Trends in reported marijuana vaping among US adolescents, 2017-2019. JAMA. 2019;323:475-6. https://doi.org/10.1001/jama.2019. 20185 A paper estimating the national prevalence of youth marijuana e-cigarette use in 2019.

11. Miech R, Johnston L, O'Malley PM, Bachman JG, Patrick ME. Trends in adolescent vaping, 2017-2019. N Engl J Med. 2019;381:1490-1. https://doi.org/10.1056/NEJMc1910739 A paper estimating the national prevalence of youth e-cigarette use in 2019.

12. Cullen K, Ambrose B, Gentkze A, Apelberg B, Jamal A, King B. Notes from the field: use of electronic cigarettes and any tobacco product among middle and high school students - $\mathrm{u}=$ United
States, 2011-2018. MMWR Morb Mortal Wkly Rep. 2018;67: 1276-7. https://doi.org/10.15585/mmwr.mm6745a5.

13. Vallone D, Cuccia A, Briggs J, Xiao H, Schillo B, Hair E. Electronic cigarette and JUUL use among adolescents and young adults. JAMA Pediat. 2020;174:277-86. https://doi.org/10.1001/ jamapediatrics.2019.5436.

14. Nicksic N, Do E, Barnes A. Cannabis legalization, tobacco prevention policies, and cannabis use in E-cigarettes among youth. Drug Alcohol Depend. 2020;206:107730. https://doi.org/10.1016/j. drugalcdep.2019.107730.

15. Gentzke A, Creamer M, Cullen K, Ambrose B, Willis G, Jamal A, et al. Vital signs: tobacco product use among middle and high school students - United States, 2011-2018. MMWR Morb Mortal Wkly Rep. 2019;68:157-64. https://doi.org/10.15585/ mmwr.mm6806e1.

16. King B, Gammon D, Marynak K, Rogers T. Electronic cigarette sales in the United States, 2013-2017. JAMA. 2018;320:1379-80. https://doi.org/10.1001/jama.2018.10488.

17. Nardone N, Helen G, Addo N, Meighan S, Benowitz N. JUUL electronic cigarettes: nicotine exposure and the user experience. Drug Alcohol Depend. 2019;203:83-7. https://doi.org/10.1016/j. drugalcdep.2019.05.019.

18. Goniewicz M, Boykan R, Messina C, Eliscu A, Tolentino J. High exposure to nicotine among adolescents who use JUUL and other vape pod systems ('pods'). Tob Control. 2018;28:676-7. https:// doi.org/10.1136/tobaccocontrol-2018-054565.

19. Stanton C, Bansal-Travers M, Johnson A, Sharma E, Katz L, Ambrose B, et al. Longitudinal e-cigarette and cigarette use among US youth in the PATH study (2013-2015). J Natl Cancer Inst. 2019;111:1088-96. https://doi.org/10.1093/jnci/djz006.

20. Miech R, Patrick M, O'Malley P, Johnston L. E-cigarette use as a predictor of cigarette smoking: results from a 1-year follow-up of a national sample of 12th grade students. Tob Control. 2017;26: e106-11. https://doi.org/10.1136/tobaccocontrol-2016-053291.

21. McCabe S, West B, McCabe V. Associations between early onset of E-cigarette use and cigarette smoking and other substance use among US adolescents: a national study. Nicotine Tob Res. 2018;20:923-30. https://doi.org/10.1093/ntr/ntx231.

22. Audrain-McGovern J, Stone M, Barrington-Trimis J, Unger J, Leventhal A. Adolescent E-cigarette, hookah, and conventional cigarette use and subsequent marijuana use. Pediatrics. 2018;142: e20173616. https://doi.org/10.1542/peds.2017-3616.

23. Ksinan A, Spindle T, Thomas N, Eissenberg T, Spit for Science Working group, Dick D. E-cigarette use is prospectively associated with initiation of cannabis among college students. Addict Behav. 2020. https://doi.org/10.1016/j.addbeh.2020.106312.

24. Dai H, Catley D, Richter K, Goggin K, Ellerbeck E. Electronic cigarettes and future marijuana use: a longitudinal study. Pediatrics. 2018;141:e20173787. https://doi.org/10.1542/peds. 2017-3787.

25. Rigsby D, Keim S, Adesman A. Electronic vapor product usage and substance use risk behaviors among U.S. high school students. J Child Adolesc Psychopharmocol. 2019;29:545-53.

26. Grant J, Lust K, Fridberg D, King A, Chamberlain S. E-cigarette use (vaping) is associated with illicit drug use, mental health problems, and impulsivity in university students. Ann Clin Psychiatry. 2019;31:27-35.

27. Saddleson M, Kozlowski L, Giovino G, Goniewicz M, Mahoney M, Homish G, et al. Enjoyment and other reasons for electronic cigarette use: results from college students in new york. Addict Behav. 2015;54:33-9. https://doi.org/10.1016/j.addbeh.2015.11. 012 .

28. Evans-Polce R, Patrick M, Lanza S, Miech R, O'Malley P, Johnston L. Reasons for vaping among U.S. 12th graders. J Adolesc Health. 2018;62:457-62. https://doi.org/10.1016/j.jadohealth.2017.10.009. 
29. Patrick M, Miech R, Carlier C, O'Malley P, Johnston L, Schulenberg J. Self-reported reasons for vaping among 8th, 10th, and 12th Graders in the US: nationally-representative results. Drug Alcohol Depend. 2016;165:275-8. https://doi.org/10.1016/j. drugalcdep.2016.05.017.

30. Leavens E, Stevens E, Brett E, Leffingwell T, Wagener T. JUUL in school: JUUL electronic cigarette use patterns, reasons for use, and social normative perceptions among college student ever users. Addict Behav. 2019;99:106047. https://doi.org/10.1016/j.addbeh. 2019.106047.

31. Tsai J, Walton K, Coleman B. Reasons for electronic cigarette use among middle and high school students - national youth tobacco survey, United States, 2016. Mmwr. 2018;67:196-200. https://doi. org/10.15585/mmwr.mm6706a5.

32. Hong H, McConnell R, Liu F, Urman R, Barrington-Trimis J. The impact of local regulation on reasons for electronic cigarette use among southern California young adults. Addict Behav. 2019;91: 253-8. https://doi.org/10.1016/j.addbeh.2018.11.020.

33. Wang T, Gentzke A, Creamer M, Cullen K, Holder-Hayes E, Sawdey M, et al. Tobacco product use and associated factors among middle and high school students - United States, 2019. MMWR Surveill Summ. 2019;68:1-22. https://doi.org/10.15585/ mmwr.ss6812a1.

34. Biener L, Song E, Sutfin E, Spangler J, Wolfson M. Electronic cigarette trial and use among young adults: reasons for trial and cessation of vaping. Int J Environ Res Public Health. 2015;12: 16019-26. https://doi.org/10.3390/ijerph121215039.

35. Marynak K, Ali F, Schauer G, Tynan M, King B. Use and reasons for use of electronic vapour products shaped like USB flash drives among a national sample of adults. Tob Control. 2019;28:685-8. https://doi.org/10.1136/tobaccocontrol-2019-054932.

36. Goldenson N, Leventhal A, Simpson K, Barrington-Trimis J. A review of the use and appeal of flavored electronic cigarettes. Curr Addict Rep. 2019;6:98-113. https://doi.org/10.1007/s40429019-00244-4 Useful review on youth interest in flavored ecigarettes.

37. Harrell M, Weaver S, Loukas A, Creamer M, Marti C, Jackson C, et al. Flavored e-cigarette use: characterizing youth, young adult, and adult users. Prev Med Rep. 2016;5:33-40. https://doi.org/10. 1016/j.pmedr.2016.11.001.

38. Ambrose B, Day H, Rostron B, Conway K, Borek N, Hyland A, et al. Flavored tobacco product use among US youth aged 12-17 years, 2013-2014. JAMA. 2015;314:1871-3. https://doi.org/10. 1001/jama.2015.13802.

39. Pepper J, Ribisl K, Brewer N. Adolescents' interest in trying flavored E-cigarettes. Tob Control. 2016;25:ii62-6. https://doi.org/10. 1136/tobaccocontrol-2016-053174.

40. Morean M, Butler E, Bold K, et al. Preferring more e-cigarette flavors is associated with e-cigarette use frequency among adolescents but not adults. Plos. 2018;13:e0189015. https://doi.org/10. 1371/journal.pone.0189015.

41. FDA, U.S., Enforcement priorities for electronic nicotine delivery system (ENDS) and other deemed products on the market without premarket authorization (2020). Retrieved from https://www.fda. gov/media/133880/download. Accessed 2 Jan 2021.

42. FDA issues official guidance on new federal flavor ban. (2020). Retrieved from https://countertobacco.org/fda-issues-officialguidance-on-new-federal-flavor-ban/. Accessed 2 Jan 2021.

43. Tobacco Control Law [Internet]. Mass.gov. 2019. [cited 2020 Sep 11]. Available from: https://www.mass.gov/guides/2019-tobaccocontrol-law. Accessed 02 Jan 2021.
44. Gorukanti A, Delucchi K, Ling P, Fisher-Travis R, Halpern-Felsher B. Adolescents' attitudes towards e-cigarette ingredients, safety, addictive properties, social norms, and regulation. Prev Med. 2017;94:65-71. https://doi.org/10.1016/j.ypmed.2016.10.019.

45. Stevens E, Hébert E, Tackett A, Leavens E, Wagener T. Harm perceptions of the JUUL E-cigarette in a sample of ever users. Int J Environ Res Public Health. 2020;17:4755. https://doi.org/10. 3390/ijerph17134755.

46. Russell C, Katsampouris E, Mckeganey N. Harm and addiction perceptions of the JUUL e-cigarette among adolescents. Nicotine Tob Res. 2020;22:713-21. https://doi.org/10.1093/ntr/ntz183.

47. Gaiha S, Duemler A, Silverwood L, Razo A, Halpern-Felsher B, Walley S. School-based e-cigarette education in Alabama: impact on knowledge of e-cigarettes, perceptions and intent to try. Addict Behav. 2021;112:106519. https://doi.org/10.1016/j.addbeh.2020. 106519.

48. Amrock S, Lee L, Weitzman M. Perceptions of e-cigarettes and noncigarette tobacco products among US youth. Pediatrics. 2016;138:e20154306. https://doi.org/10.1542/peds.2015-4306.

49. US Department of Health and Human Services. E-cigarette use among youth and young adults: a report of the Surgeon General. Atlanta, GA: US Department of Health and Human Services, CDC, National Center for Chronic Disease Prevention and Health Promotion, Office on Smoking and Health; 2016. https://ecigarettes.surgeongeneral.gov/documents/2016_SGR_Full Report_non-508.pdf. Accessed 5 Jan 2021.

50. Strombotne K, Buckell J, Sindelar J. Do JUUL and e-cigarette flavours change risk perceptions of adolescents? evidence from a national survey. Tob Control. 2020;30:199-205. https://doi.org/10. 1136/tobaccocontrol-2019-055394.

51. Krishnasamy V, Hallowell B, Ko J, Board A, Hartnett KP, Salvatore PP, et al. Update: characteristics of a nationwide outbreak of E-cigarette, or vaping, product use-associated lung injury United States, August 2019-January 2020. MMWR. 2020;69:904.

52. Werner A, Koumans E, Chatham-Stephens K, Salvatore P, Armatas $\mathrm{C}$, Byers $\mathrm{P}$, et al. Hospitalizations and deaths associated with EVALI. N Engl J Med. 2020;382:1589-98. https://doi.org/10. 1056/NEJMoa1915314.

53. Outbreak of lung injury associated with the use of E-cigarette, or vaping, products. (2020). Retrieved from https://www.cdc.gov/ tobacco/basic information/e-cigarettes/severe-lung-disease.html. Accessed 15 Dec 2020.

54.• Miech R, Leventhal A, Johnston L, O'Malley P, Patrick M, Barrington-Trimis J. Trends in use and perceptions of nicotine vaping among US youth from 2017 to 2020 . JAMA Pediatr. 2020;15. https://doi.org/10.1001/jamapediatrics.2020.5667 First paper exploring the potential affects of EVALI on youth perceptions of e-cigarettes.

55. Li D, Croft D, Ossip D, Xie Z. Are vapers more susceptible to COVID-19 infection? Medrxiv. 2020. https://doi.org/10.1101/ 2020.05.05.20092379.

56.• Gaiha S, Cheng J, Halpern-Felsher B. Association between youth smoking, electronic cigarette use, and COVID-19. J Adolesc Health. 2020;67:519-23. https://doi.org/10.1016/j.jadohealth. 2020.07.002 First paper exploring associations between youth e-cigarette use and COVID-19.

Publisher's Note Springer Nature remains neutral with regard to jurisdictional claims in published maps and institutional affiliations. 